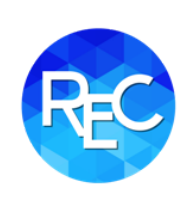

Revista Espaço do Currículo

ISSN 1983-1579

Doi: 10.22478/ufpb.1983-1579.2019v12n3.46185 http://periodicos.ufpb.br/ojs2/index.php

\title{
CONTRIBUIÇÕES DO MATERIALISMO HISTÓRICO DIALÉTICO PARA O PROJETO EM REDE OBSERVATÓRIO DA FORMAÇÃO DE PROFESSORES DE ARTES VISUAIS
}

\author{
CONTRIBUCIONES DEL MATERIALISMO HISTÓRICO DIALÉTICO PARA EL PROYECTO EN RED \\ OBSERVATORIO DE LA FORMACIÓN DE PROFESORES DE ARTES VISUALES
}

Rosana Soares ${ }^{1}$

\begin{abstract}
Resumo: O artigo discute a escolha do método cientifico nas pesquisas sobre formação docente em artes visuais. Tal tarefa requer dos pesquisadores uma escolha teórica e metodológica entre as múltiplas abordagens da pesquisa científica. Quando pesquisadores e pesquisadoras elegem o materialismo histórico dialético na investigação está assumindo uma visão de mundo, de homem e de sociedade em sua concentricidade. Pesquisar a partir da matriz teórica marxista significa adentrar nos fenômenos sociais indo além de sua imediaticidade. Como uma ciência filosófica, o materialismo histórico dialético representa no campo da pesquisa o salto fundamental de análise concreta do real e a possibilidade de ação no campo da transformação social. Defende-se assim que o projeto em rede Observatório da Formação de Professores de Artes Visuais nas suas investigações sobre arte e formação docente encontra no materialismo histórico dialético as contribuições necessárias para o desenvolvimento de suas investigações.
\end{abstract}

Palavras-chave: Método; Epistemologia; Pesquisa educacional; Formação docente.
Resumen: El artículo discute la elección del método científico en las investigaciones sobre formación docente en artes visuales. Tal tarea requiere de los investigadores una elección teórica y metodológica entre los múltiples enfoques de la investigación científica. Cuando investigadores e investigadores eligen el materialismo histórico dialéctico en la investigación está asumiendo una visión de mundo, de hombre y de sociedad en su concentricidad. Buscar a partir de la matriz teórica marxista significa adentrarse en los fenómenos sociales yendo más allá de su inmediatez. Como una ciencia filosófica, el materialismo histórico dialéctico representa en el campo de la investigación el salto fundamental de análisis concreto de lo real y la posibilidad de acción en el campo de la transformación social. Se defiende así que el proyecto en red Observatorio de la Formación de Profesores de Artes Visuales en sus investigaciones sobre arte y formación docente encuentra en el materialismo histórico dialéctico las contribuciones necesarias para el desarrollo de sus investigaciones.

Palabras clave: Método; Epistemología; Investigación educativa; Formación docente.

\section{ELEMENTOS CENTRAIS NA FORMAÇÃO DOCENTE}

As pesquisas sobre o tramado campo formativo de professoras e professores de artes visuais reflete a inquietação dos educadores sobre a práxis². A formação docente e o ensino da arte que buscam a emancipação dos sujeitos encontram desafios cotidianos quando objetivam um ensino de arte que promova ao aluno a apropriação do conteúdo universal da obra de arte, para que instrumentalizado, possa compreender a si e agir no mundo em que está inserido. O conceito de emancipação em István Mészáros (2007) atribui a educação como processo de produção e reprodução da vida social sendo um dos caminhos para a emancipação da humanidade.

Além das objetivar o debate em torno de métodos científicos eleitos nas pesquisas sobre ensino e formação de professoras e professores de artes visuais, o presente texto levanta outras questões nevrálgicas sobre a obra de arte, objetividade e subjetividade, conteúdo e forma a partir de algumas

\footnotetext{
${ }^{1}$ Doutora em Educação pela Universidade Federal da Bahia. Professora da Universidade Federal do Recôncavo da Bahia - UFRB. E-mail: rosana arteso9@yahoo.com.br ORCID: http://orcid.org/0000-0003-2684-7587.

${ }^{2} \mathrm{O}$ termo práxis é aqui utilizado a partir dos estudos de Karl Marx que a define como atividade de interação entre o homem e a natureza, na qual o homem é capaz de transformar o seu meio.
} 
considerações de Karl Marx, Frederich Engels (2010) e Görgy Lukács (1968).

Para apontar às contribuições do materialismo histórico dialético as pesquisas do projeto em rede Observatório de Formação de professores de arte visuais além de uma sucinta fundamentação teórica, referenciam-se duas pesquisas que foram construídas a partir do método marxista e indaga-se sobre a presença tímida do referencial marxista na formação docente em artes visuais. Alarga-se o debate na defesa da compreensão da arte e da educação como campos formativos que não são sinônimos mas que convergem em vários pontos, gerando a necessidade de aproximação do ensino da arte com os fundamentos da Pedagogia Histórico-Crítica.

\section{O MATERIALISMO HISTÓRICO DIALÉTICO E A PESQUISA SOBRE FORMAÇÃO DOCENTE}

As contribuições do Materialismo Histórico Dialético ${ }^{1}$ para o projeto em rede Observatório da Formação de Professores de Artes Visuais ${ }^{3}$ começa com a escolha do enfoque metodológico marxiano. "Todo objeto de pesquisa tem sua existência objetiva" (NETTO, 2011, p.22) e o método possibilitará aos pesquisadores desvelar o aparente e chegar de forma clarificada aos processos formativos das licenciadas e dos licenciados.

Segundo o autor no livro O que é o Marxismo, o materialismo dialético é uma teoria geral do ser que contrapõe o metafísico privilegiando o movimento e a contradição tendo o mundo material como dado primário que se torna secundário na consciência - seu reflexo. Já o materialismo histórico é a aplicação do materialismo dialético à sociedade. No entanto, o método não deve ser entendido como um conjunto de regras formais para descrever um objeto investigado, tão pouco um conjunto de regras que o sujeito que pesquisa escolhe para o seu objeto de investigação.

Muito além de um conjunto de regras e instrumentos, as contribuições do materialismo histórico dialético estão no fato de que a partir de seus fundamentos os processos de formação de professoras e de professores de artes visuais passam a ser vistos como um conjunto de conceitos que podem e devem ser analisados constantemente em profundo diálogo com o campo real dessa formação. Reconhece-se, assim, a necessidade de uma análise crítica permanente sobre o que de fato propõe determinados conceitos aos licenciados em artes visuais e como tal formação vai influenciar as práticas pedagógicas.

O método de Marx propõe extrair dos fenômenos as categorias necessárias para se chegar ao conhecimento - a essência -, pois não cabe aos pesquisadores que assumem o método marxiano produzir conhecimento com base em inspiração, percepção, compreensão. Sobre as análises, Marx e Engels declaram, segundo Netto (2011, p. 26), que "não se parte daquilo que os homens dizem, imaginam ou representam, tampouco dos homens pensados, imaginados ou representados para, a partir daí, chegar aos homens de carne e osso; parte-se dos homens realmente ativos".

Nessa perspectiva epistemológica, as interpretações da aparência do fenômeno são pontos de partida, mas não se resumem a elas, pois os pesquisadores têm a tarefa de descrever de forma objetiva os dados encontrados. Todavia, mesmo sendo o sujeito o ator da pesquisa, é o objeto quem vai revelar o seu contexto e sua atuação social. "É a estrutura e a dinâmica do objeto que comandam os procedimentos do pesquisador". O método implica, para Marx, uma determinada posição (perspectiva) do sujeito que pesquisa: aquela em que se põe o pesquisador para, na sua relação com o objeto, extrair dele as suas múltiplas determinações (NETTO, 2011, p. 53).

Sendo assim, o pesquisador que assume o método marxiano desenvolve um árduo trabalho de pesquisa, um confronto real com seu objeto e com os instrumentos do passado. O materialismo histórico dialético, como enfoque metodológico, possibilita ao pesquisador entender o modo humano de produção em uma concepção de realidade. O mundo tem existência material e pode ser conhecido racionalmente e "não se pode conceber o mundo como um conjunto de coisas acabadas, mas como um conjunto de processos" (MARX-ENGELS, apud NETTO, 2011 p. 31).

O projeto em rede Observatório da Formação de Professores de Artes Visuais surge de forma

${ }_{3}^{3}$ Disponível em: http://observatorio.cead.udesc.br/ 
legítima em consonância com o método histórico dialético quando faz o diagnóstico entendendo que a formação de professores e professoras de artes visuais é um fenômeno latente e o que se tem de conhecimento desse fenômeno não é suficiente. Assim, definido o campo de pesquisa para o grupo, segue o movimento, como lembra Netto (2011, p. 40), "uma vez determinado o seu objeto, põe-se a Marx a questão de como conhecê-lo - põe-se a questão do método".

Para Gamboa (2007), as pesquisas que assumem a matriz filosófica do materialismo histórico manifestam interesse de transformar. Frente à multiplicidade de compreensões sobre formação de professoras e professores de artes visuais, tal postura investigativa permitirá como salienta o autor, ultrapassar a percepção imediata registrando dados concretos que revelam a relação entre totalidade e suas partes, permitindo a síntese. "O concreto é concreto porque é a síntese de muitas determinações, isto é, unidade do diverso. Por isso, o concreto aparece no pensamento como o processo da síntese, como resultado, não como ponto de partida" (MARX, 1859, p. 06).

Entre as inúmeras contribuições do materialismo histórico dialético para o projeto em rede Observatório da Formação de Professores de Artes Visuais, tem-se como central a possibilidade de se construir pontes para a coletividade, condição essencial de todo projeto emancipatório. Goldman (1993) lembra que para o materialismo dialético não há consciência supra individual, antes, a consciência coletiva ou de consciência de classe é o conjunto de consciências individuais e resultam da mútua influência dos homens uns nos outros e de suas ações sobre a natureza.

O cultivo do homem como ser responsável pelo seu destino nos processos educacionais, a partir do materialismo histórico, impregna esses sujeitos de força para buscar o que precisa: condições de uma vida melhor, no coletivo. "Em vez de gerar a passividade e a resignação, o materialismo é um apelo à ação; permite reconhecer com precisão o que é possível, e definir o poder efetivo do homem" (Idem), ou seja, "conhecer para transformar" (GAMBOA, 2007, p. 119).

Para o projeto em rede Observatório da Formação de Professores de Artes, o materialismo histórico dialético permitirá identificar a conjuntura dessa formação a partir da hipótese do que existe hoje: uma formação em artes visuais que precisa de reflexão crítica e transformações urgentes. Com o método marxiano, as pesquisas assumem a intepretação da realidade quando compreendem a mudança dialética ou o constante movimento do presente, passado e futuro. Perpassa também considerar a ação recíproca que desencadeia questionamentos constantes e a contradição como categoria intrínseca dos fenômenos pesquisados. Por fim, o avanço para a transformação do que temos são pontos que alavancam a superação para a emancipação.

De forma ampliada, pode-se concluir que entre as contribuições do materialismo histórico dialético para o projeto em rede Observatório da Formação de Professores de Artes Visuais está, além das já apontadas, a tomada de consciência da intencionalidade do ato pedagógico e, consequentemente, do ato formativo - e com isso a necessidade da constante reflexão crítica em torno da formação em artes visuais.

Convém ressaltar que investigar a formação em artes visuais, na perspectiva do materialismo histórico dialético, exige do pesquisador a análise do movimento inerente aos processos históricos e isso significa uma ruptura com o senso comum de entendimento da realidade social, contraditória e tencionada por sujeitos históricos. Eis a tarefa do projeto em rede Observatório da Formação de Professores de Artes Visuais ao assumir o materialismo histórico dialético em suas pesquisas: superar a imediaticidade do objeto e identificar as determinações que o compõe, pois o concreto está dado, mas não está revelado.

\section{A PEDAGOGIA HISTÓRICO-CRÍTICA E O ENSINO DA ARTE}

As pesquisas sobre educação e formação docente a partir do materialismo histórico dialético encontra na concepção pedagógica denominada Pedagogia Histórico-Crítica um aliado fundamental. A Pedagogia Histórico-Crítica define a educação como um ato intencional, que objetiva mediar as relações 
sociais tendo como preocupação central a compreensão da humanidade produzida historicamente. Uma prática social educativa é como que a Pedagogia Histórico-Crítica entende a educação: lugar onde professores e alunos dividem tarefas diferenciadas no processo de desenvolvimento do coletivo. E no coletivo que se constrói a busca de soluções dos problemas que surgem neste movimento da prática social, visando às transformações necessárias.

Demerval Saviani (1994) observa que a Pedagogia Histórico-Crítica tem como objetivo compreender o campo educacional com base no desenvolvimento histórico objetivo. A Pedagogia Histórico-Crítica nos permite, segundo o autor, compreender a educação escolar que temos hoje, identificando os resquícios históricos das transformações que lhe são próprias. Nascida das necessidades oriundas das práticas escolares, é a realidade escolar seu lugar de discussão e atuação. Foram as necessidades educativas que geraram a Pedagogia Histórico-Crítica, que a partir do materialismo histórico, busca compreender a história a partir do "desenvolvimento material, da determinação das condições materiais da existência humana” (Idem, p.88).

Portanto, o homem é entendido como sujeito de ação, reconhecendo com isso a sua marca distintiva de produzir a sua existência, consequentemente, provocar as mudanças na natureza para nela viver, ou seja, o homem tem a capacidade e o potencial para transformar. Essa transformação se dá através do trabalho, que não sendo estanque, se modifica ao longo do tempo. O desenvolvimento histórico, diz Saviani, nada mais é do que a constatação desse processo, onde o homem age na natureza através do trabalho e constrói o mundo humano.

"No princípio, o homem agia sobre a natureza coletivamente e a educação coincidia com o próprio ato de agir e existir, com o trabalho, portanto. $O$ ato de viver era o ato de se formar homem, de se educar" (SAVIANI, 2007, p. 94). A arte pertence ao mundo dos homens, logo se materializa no trabalho. Como nos lembra Maiakovski (1893 - 1930) a arte não é espelho, mas antes martelo que forja o mundo.

Nas pesquisas em arte e educação a ausência dos pressupostos da Pedagogia Histórico-Crítica já revela uma aresta que deve ser problematizada.

“(...) A escola tem uma função especificamente educativa, propriamente pedagógica, ligada a questão do conhecimento; é preciso, pois resgatar a importância da escola e reorganizar o trabalho educativo, levando em conta o problema do saber sistematizado, a partir do qual se define a especificidade da educação escolar. (SAVIANI, 1994, p. 98).

Um ensino da arte distanciado dos fundamentos emancipatórios presente na Pedagogia Histórico-Crítica merece atenção dos pesquisadores que compõe o Observatório de Formação de Professores.

\section{CONVERGÊNCIAS DA ARTE COM A EDUCAÇÃO: um debate necessário}

Arte e educação não são sinônimas, mas podem convergir em alguns campos formativos quando assumem objetivos comuns. Problematizar a Arte na educação de forma contínua favorece a discussão em torno das implicações do encontro de duas áreas de conhecimento que atuam na formação dos sujeitos. Tal delimitação se faz necessária para que a convergência dos saberes seja potencializada no projeto emancipatório de formação dos sujeitos.

Defende-se a arte como uma forma específica de ver o mundo. Os fenômenos são conhecidos por áreas de conhecimento como filosofia e ciência. No que se refere à arte, podemos compreender sua importância ao entendermos sua forma única de registro e testemunho do mundo dos homens. Fischer (2002) defende que o homem anseia por unir na arte o seu "Eu" limitado com uma existência humana coletiva, tal afirmativa nos auxilia compreender a arte em sua complexidade.

Entende-se a obra de arte e os artistas como representantes do desvio da norma. Esse conceito tem uma sonoridade agradável, tem cheiro de liberdade criativa, de rompimento, rebelião. Infla a consciência sobre a normatividade social, ao mesmo tempo em que sugere a sua transgressão de forma 
objetiva. Longe do conceito jurídico, a criação da obra de arte no desvio da norma é a infidelidade necessária do aprisionamento do sentir criativo. O artista a partir do desvio da norma assume a poética não como um processo rotineiro, mas como uma tomada de posição frente ao mundo. Assim, desviar da norma representa a consciência da complexidade da obra de arte frente ao seu destino: questionar o mundo capitalista que nos arrasa, formata, desumaniza. O desvio da norma é resistência; Arte é conhecimento do mundo concreto construído por sujeitos sociais em contextos culturais diversos.

A arte possui saberes e conhecimentos concretizados em objetos artísticos que acessamos ao dominarmos os códigos estéticos das obras de arte. Saviani (2004) aponta para existência de diversos tipos de saberes e conhecimentos como a sensível, o conhecimento intelectual, o conhecimento artístico e estético, o conhecimento religioso, etc. entre os vários saberes existentes. O saber que diretamente interessa à educação está vinculado ao trabalho educativo e resulta na aprendizagem. Eis, então, o desafio da convergência da arte com a educação.

A ação docente no ensino da arte requer considerar o "deslocamento" da obra de arte do atelier, dos museus e das galerias para o campo objetivo da educação; tal movimento vai compor os desafios do trabalho educativo. Compreender o lugar da Arte na Educação e os significados deste encontro exige diferenciar o trabalho do artista do trabalho do professor em pontos estratégicos, pois o trabalho pedagógico é pautado na objetividade.

Talvez nesse momento do texto, os leitores formados na área da arte farão reflexões acerca dessa afirmação sobre o trabalho pedagógico ser pautado na objetividade. Não quero com isso defender a impessoalidade ou o caráter positivista na ação docente e sim que a educação emancipatória perpassa oportunizar aos sujeitos em condição escolar à apropriação do conteúdo universal da obra de arte, para compreender a si e agir no mundo em que estão inseridos. Tal defesa baseia-se na necessidade de construção de um ensino da arte significativo, gerador de vivência e experiência com potencial formativo para vida. Objetividade na educação significa a defesa do ensino de arte que busca a formação integral dos sujeitos e que tem a obra de arte como coluna central de práticas docente emancipatórias.

Ao apontar o caráter objetivo da educação questiona-se a falsa dualidade objetividade/subjetividade no processo criador do artista e também nas práticas artísticas desenvolvidas nas aulas de arte. Para Marx (2010), o trabalho artístico não seria possível sem a associação do caráter objetivo e subjetivo, pois ambos são indissociáveis. Ora, se a obra de arte é construída e pautada nos dois elementos, a discussão em torno do ensino de arte que priorize um dos elementos não se sustenta. Assim, quando defendemos o caráter objetivo da educação e a necessidade de se considerar tal objetividade no ensino da arte, estamos tratando dos objetivos da ação pedagógica.

A partir disso, o que chamamos de convergência do ensino da arte com a educação se pauta na concretude do processo educacional de sujeitos reais e historicamente determinado. Defende-se, assim, que práticas formativas pautadas na percepção dos sujeitos não avançam para a compreensão dos fenômenos e percorre metade do caminho, se distanciando dos processos que levam às mudanças. Perde seu caráter objetivo e se distancia da educação.

A educação emancipatória prioriza as transformações com a proximidade da vida social e a sua relação à obra artística. Por isso, é necessário à apropriação pelo sujeito do conteúdo humano presente na obra de arte; este é o papel da mediação do professor: desenvolver a "tríplice consciência: da forma, do trabalho e do objeto" (SÁNCHEZ VÁZQUEZ, 1999 p. 100).

A tese ${ }^{4}$ de doutorado "A Educação Estética como Possibilidade de Emancipação dos Sujeitos no Ensino da Arte: Desdobramentos e Implicações" desta autora, revelou a educação estética em seus fundamentos teóricos. A análise das categorias mostrou que os educadores de uma forma geral (45 dos 51 artigos analisados) entendem que educação em arte, e especialmente a educação estética, se

${ }^{4}$ Disponível em: https://repositorio.ufba.br 
constrói com a educação dos sentidos. Em parte, pode-se afirmar que educar sensibilidades é de extrema importância desde que não se limite a ela.

Educar sensibilidades deveria ser parte do caminho e não objetivo final, principalmente no ensino da arte, porque faltaria o caráter objetivo da educação. Certamente, o leitor nesse momento se pergunta: a arte não educa pelo seu conteúdo intrínseco? Concordamos com a afirmativa de que a arte educa em seu conteúdo, mas a ação docente potencializada na educação objetivada pode concretizar a educação para a transformação.

A tese citada revelou que o ensino da $\operatorname{arte}^{5}$ de modo geral é centrado no Fazer e no Ver obras de arte. Este contato com o objeto artístico acontece, segundo os textos, na escola ou os alunos podem ser levados ao encontro delas - nos espaços urbanos, exposições ou museus - esses encontros são entendidos como experiências. No que se refere aos valores educativos cultivados pelos artigos, que priorizam a educação das sensibilidades, exige considerar que para estes “(...) o conhecimento não está centralizado no objeto e sim no sujeito (a priori), a verdade é relativa a cada sujeito que, em relação com o objeto (adequatio res ad intecllectu), interpreta-o e explica-o ao seu modo" (GAMBOA, 2008, p. 05). Assim, é possível compreender porque deixam de problematizar o objeto, no caso, a obra de arte e as suas influências ideológicas. Não está nela (a obra de arte) o ponto de interlocução dialógica sujeito e objeto, e sim no sujeito que confere significação a essa experiência. Da mesma forma, é reelaborado o papel do professor, pois os processos subjetivos estão priorizados.

Entre as várias categorias analisadas, estão as correntes teóricas que embasaram os artigos analisados. A pesquisa identificou apenas seis textos com os pressupostos da educação estética para a emancipação (representado nos conceitos dos teóricos Adolfo Sánchez Vázquez (1978) e L.S. Vygotsky (1981). A partir dos fundamentos teóricos o artigo identificado na tese por PED 11 não traz o discurso de formar sensibilidades e anuncia o objetivo da arte na educação: não se tem mais apenas a educação de sensibilidades, mas o desenvolvimento da consciência crítica, visto não ser possível ignorar que sendo produto de trabalho humano "a arte reproduz em seu meio de produção, isto é, no processo de trabalho, no ensino e na circulação da mercadoria arte, os mesmos esquemas de exclusão e dominação inerentes a qualquer outra mercadoria na mesma circunstância".

O objeto estético é "físico-perceptual", e nele o "sensível" se acha organizado "em uma forma" que o torna "significativo". Mas só tem essa tríplice e indissolúvel existência na relação entre "um sujeito e um objeto" que se concretiza ou realiza em cada situação estética que, sendo sempre singular, se encontra condicionada histórica, social e culturalmente. (SÁNCHEZ VÁZQUEZ, 1999, p. 121)

O ensino da arte nos pressupostos da emancipação não pode ser centrado na valorização dos sentimentos e das emoções ou considerar que as subjetividades e as experiências são suficientes. Ultrapassar os idealismos existentes requer pensar que a educação compõe a formação dos indivíduos e, com isso, considerar a realidade existente também na arte como parte dessa formação que, por sua vez, não pode ser desprendida de sua função social.

Karl Marx (2010) já nos alertou sobre a aparência dos fenômenos que encobrem a essência desses. Pensar sobre os fenômenos considerando as contradições é um processo a ser desenvolvido, no qual a educação para a emancipação está comprometida. Reafirmando a necessidade de consciência do real do mundo concreto, LUKÁCS (1968, p. 86) diz que "é tão fácil produzir, a partir de frutas reais, a ideia abstrata 'a fruta', quando é difícil produzir, partindo da ideia abstrata 'a fruta', frutas reais". Assim, o homem e seu cotidiano incluindo a sua produção artística, impulsionam os processos de emancipação; o ensino da arte pode ser parte do processo emancipatório.

\section{SOBRE PRÁTICAS DOCENTES E A ESCOLHA DE OBRAS DE ARTE}

As obras de arte selecionadas para a prática pedagógica são, antes de qualquer coisa, ação

\footnotetext{
${ }^{5}$ Foram analisados 55 artigos publicados na ANPAP e ANPED.
} 
consciente para a educação. Konder (1967) aponta que para Marx e Engels a arte é um aspecto dinâmico do conhecimento humano e que este conhecimento não é dado e sim, antes, um ato; ação de conhecer que leva a transformação do sujeito; é na práxis que o homem se forma enquanto ser pensante. A força formativa da arte se concentra em sua porção estética (forma e conteúdo). Será a partir de seu reflexo do real que a obra de arte se aproxima da vida social e do desenvolvimento do homem. "Literatura e arte são fenômenos sociais extremamente importantes; e, como tais, foram investigados, em sua mútua relação recíprocos com a existência social e moral do homem, pelos escritores do passado". (LUKÀCS, 2010, p.242).

A ligação da arte com o mundo e com a realidade revela sua condição de pertencimento ao homem concreto e histórico. Algumas concepções em torno da obra de arte se tornam ponto de ebulição, como por exemplo, o combate ao naturalismo e a defesa da importância da forma artística envolvida com seu conteúdo.

É uma luta na qual o marxismo continua e desenvolve as teorias que os mestres da literatura mundial sempre tiveram em relação à essência da verdadeira obra de arte: teorias segundo as quais cabe à arte representar fielmente o real em sua totalidade, de maneira a manter-se distanciada tanto da cópia fotográfica quanto do puro jogo (vazio, em última instância) com as formas abstratas. (LUKÁCS, 2010, p. 25)

Para o autor, a verdadeira arte não pode se isentar de fornecer um olhar conjugado, representando o movimento da vida humana, ou seja, sua evolução e desenvolvimento. É através da concepção dialética que "a unidade universal move o particular e o singular" (Idem, p. 26) que são específicas dos fenômenos artísticos, se concretiza.

A objetividade marxiana é uma tomada de posição do sujeito, fruto de sua consciência crítica perante a sociedade. Essa objetividade contempla a sua subjetividade representada pela dinâmica da obra de arte conferindo a ela, autenticidade enquanto criação. O diferencial da obra de arte está nessa aproximação do mundo humano sem se perder nele.

Este vínculo com o processo histórico torna a obra de arte comprometida com o mundo dos homens. Este é um ponto fundamental que pode ser estendido em nossas reflexões para nossa formação, no olhar crítico e compreensivo sobre a práxis. Mais do que isso, a clareza acerca de nossas escolhas é condição inegociável, não podemos abrir mão de nossa autoria na atuação docente.

A concentração exclusiva do talento artístico em indivíduos únicos - e a consequente asfixia de tais dotes na grande massa - deriva da divisão do trabalho. Se mesmo sob certas condições sociais, todos pudessem chegar a ser pintores magníficos, isto não excluiria, em absoluto, que cada qual fosse um pintor original - com que, também neste ponto, reduzir-se-ia a um puro absurdo a distinção entre o trabalho "humano" e o trabalho "único" (MARX e ENGELS, 2010, p. 168)

Os autores apontam a importância das condições materiais para o desenvolvimento do trabalho, incluindo aqui o trabalho artístico. A atividade artística por muito tempo foi vista como resultado do trabalho de um gênio ou como um dom e, por isso, uma condição reservada para poucos. A criação artística exige de seu criador trabalho árduo; é um processo que envolve a sua subjetividade objetivada dentro das condições dadas. Inclui sua formação intelectual artística, sua alfabetização estética, sua convivência com a arte. Todos estes fatores qualificam seu trabalho sem precisar com isso alimentar mitos em torno de sua condição humana.

Por isso, no que se refere a mediação do professor de Arte, a desmistificação em torno do trabalho do artista é fundamental para que nossos alunos saiam da escola com a compreensão da arte como trabalho material humano. O objeto de arte - como qualquer outro produto - cria um público 
capaz de compreender a arte e de fruir sua beleza. "Portanto, a produção não produz somente um objeto para o sujeito, mas também um sujeito para o objeto" (MARX e ENGELS, 2010, p. 137).

Sobre as inovações técnicas, os espaços interativos da arte contemporânea, Lukács entende a dinâmica do mundo e as transformações que sucedem, mas não aceita que tais inovações contribuam para a fragmentação do sujeito: “(...) toda obra de arte autêntica obedece e amplia, ao mesmo tempo, as leis de seu próprio gênero. E a ampliação ocorre sempre no sentido de satisfazer as "exigências do momento"”'. (LUKÁCS, 1968, p.16).

Este império exercido sobre a consciência humana pela divisão capitalista do trabalho, esta fixação do isolamento aparente dos momentos superficiais da vida capitalista, esta separação ideal de teoria e práxis, produzem - nos homens que capitulam sem resistência diante da vida capitalista - também uma cisão entre o intelecto e o mundo dos sentimentos. (Idem, p. 66)

A separação do sensível e do inteligível no ensino da Arte colabora para uma relação parcial com a obra. Na escola e na universidade ocorrem algumas práticas pedagógicas que flutuam em seu extremo: o aluno fica livre para "criar" a partir de sua subjetividade, onde tudo é válido por ser a expressão particular do sujeito; ou o estudo acerca da biografia do artista, do movimento histórico do qual a obra faz parte. A busca do equilíbrio entre as abordagens pode ser um caminho para a educação comprometida com a emancipação dos sujeitos através da apropriação dos saberes que a arte representa para a humanidade. A inseparabilidade arte e vida é condição para a arte verdadeira: "A concepção do mundo do escritor abre-lhe caminho para uma consideração sem preconceito da realidade, ou se interpõe entre o escritor e a realidade uma barreira que impede sua plena entrega as riquezas da vida social”. (LUKÁCS, 2010, p. 76)

Sobre essa concepção da arte pela arte junto com o acelerado ritmo da vida moderna, Lukács escreve que as orientações filosóficas subjetivistas assumem de forma perigosa o pensamento em torno da criação artística. Supervalorizando a subjetividade e dissolvendo a objetividade retira o homem do processo criativo, vagando nas impressões.

Quanto mais solidamente os pensamentos e sentimentos dos homens se mantiverem prisioneiros do pobre e abstrato cárcere da espontaneidade, tanto maior será a margem de segurança das classes dominantes. Compreende-se que isto diga respeito particularmente ao movimento operário; mas vale igualmente para todos os campos da vida cultural. (Idem, p. 109)

Lukács afirma que a clareza conceitual do marxismo em seus princípios fundamentais na esfera da criação enquanto atividade humana é um salto qualitativo sem precedentes. Defender o desenvolvimento integral do homem através da luta emancipadora do proletariado, significa também a condenação do sistema capitalista que impõe "o fracionamento da totalidade concreta do homem em especializações abstratas” (LUKÁCS, 2010, p. 20).

\section{A PESQUISA NA FORMAÇÃO DE PROFESSORES E DE PROFESSORAS}

Ao iniciar a carreira docente como licenciada em artes visuais muitas dúvidas movimentam o cotidiano de trabalho. A difícil ponte da teoria aprendida na universidade com a prática da sala de aula geram insatisfações múltiplas e perguntas que nem sempre tinham respostas. As particularidades da Arte e da Educação são potencializadas ao mesmo tempo que convergem a partir dos campos específicos de saberes, para a formação dos sujeitos.

Tentando compreender para além das aparências dos fenômenos presente na educação, faz-se necessário expandir o pensamento sobre o que exatamente está envolvido neste processo, o que incluía conhecer as várias teorias que influenciam o ensino da arte e o campo da educação. Ao conhecer os fundamentos teóricos, o passo seguinte era investigar como elas atuam em nossa prática docente. 
A dissertação de mestrado ${ }^{6}$ "Concepções Pedagógicas nos Currículos de Artes Visuais em Santa Catarina”, desta autora, defendida em 2009, pela Universidade do Estado de Santa Catarina (UDESC), permitiu apontarmos que os currículos que formavam os professores de arte em Santa Catarina eram norteados pela Concepção Pedagógica Renovadora e Produtivista. Sua importância está na defesa de que conhecer a trajetória do ensino da arte e as concepções pedagógicas que a constitui auxilia na construção de uma prática docente onde a reflexão sobre o ato educativo se torna constante: o que ensinar? Como ensinar? Para quê ensinar? Simples e ao mesmo tempo complexo em suas contradições.

A influência das concepções pedagógicas na formação e na prática docente aponta a compreensão de sujeito e de educação, ou seja, compõe parte davisão de mundo dos educadores e educadoras. Compreender os valores que estão embutidos nestas formas de saberes e atuar nestes campos de conhecimento para a educação dos sujeitos é fundamental. A consciência do educador acerca de sua formação e o que está incluído nela, sua base teórica e filosófica é tarefa constante de discussão para que sua prática pedagógica seja crítica e reflexiva. Poderemos identificar problemas, buscar soluções e reparar as arestas existentes.

Apesar do discurso emancipador presente nos Parâmetros Curriculares de Santa Catarina (aparência) e também nas apresentações dos cursos de licenciatura que formavam os professores de arte, a pesquisa revelou (essência) uma formação baseada na concepção Renovadora e Produtivista, e concluiu que não seria possível munir os professores dos saberes necessárias para uma educação que não fosse essa: reproduzir o que já estava posto.

Tal alcance analítico crítico somente foi possível devido a escolha do método de análise do objeto pesquisado. A pesquisa ultrapassou a aparência do fenômeno e apontou a essência da formação de professores em Santa Catarina, que contrariava o discurso de apresentação dos cursos e dos parâmetros curriculares do estado: a pesquisa permitiu ir "além da percepção imediata, na busca do concreto para as relações entre totalidade e suas partes alcançando a síntese para então contribuir de forma ativa nas mudanças desejadas" (GAMBOA, 2003, p. 402). Ao identificar a contradição entre discurso e currículo formativo, revelou-se uma lacuna tornando urgente a investigação dos currículos e do ensino de arte com diferentes enfoques.

A partir dessa análise crítica compreendi que identificar e discutir o currículo é um dos pontos chaves para se superar os desafios para a construção de um ensino da arte para a emancipação dos sujeitos. Se os professores em Santa Catarina estavam sendo formados nos princípios da Concepção Pedagógica Renovadora e Produtivista, como poderiam lutar por algo diferente, por uma educação emancipadora? Respondeu-se assim a problemática que se iniciou lá em minha sala de aula ao identificar o papel de cada um dos envolvidos nessa estrutura de reprodução do poder e tensão na qual a escola está inserida.

Se a pesquisa citada em 2009 anunciou uma problemática na formação de professores nos cursos de licenciatura em Artes Visuais em Santa Catarina, a discussão ganhou força a partir de pesquisas que utilizaram o método do materialismo dialético. Nesse sentido o Observatório de Formação de Professores cumpre um papel fundamental ao assumir em suas pesquisas o referencial marxiano.

\section{CONCLUSÃO}

O texto buscou apontar a importância do Materialismo Histórico Dialético para o Projeto em Rede Observatório da Formação de Professores de Artes Visuais, legitimando o seu protagonismo a partir da escolha do método marxiano em suas pesquisas cientificas. Tal afirmativa se deve ao fato que as pesquisas em artes a partir do método são em número reduzido. De modo geral o pensamento de Marx é pouco discutido pelos pesquisadores da área de arte e ensino e nas universidades que formam professores de arte, as duas pesquisas citadas não deixam dúvida dessa ausência, tanto nos currículos como nos artigos analisados.

\footnotetext{
${ }^{6}$ http://tede.udesc.br/
} 
Outro ponto foi à necessidade de se definir as áreas de conhecimentos em suas especificidades sem esquecer a trama teórica que permite convergência da arte e da educação. Nesse viés, a Pedagogia Histórico-Crítica define a educação como um ato intencional. Quais são nossas intenções ao ensinar a arte? Ao definir a educação como uma prática social, professores e alunos dividem tarefas diferenciadas no processo de desenvolvimento do coletivo; ao ensinar arte só podemos ter como intenção a transformação social e um ensino da arte para a emancipação.

Por isso insistimos no caráter objetivo da educação; que resulta no questionamento da falsa dualidade objetividade e subjetividade na poética e no ensino da arte. A separação do sensível e do inteligível no estudo da Arte colabora para uma relação parcial com a obra. Educar sensibilidades é tão fundamental quando avançar na investigação do repertório imagético do mundo da arte em seu contexto sociopolítico, histórico, material e dialético.

Pontuamos também a necessidade de discussão em torno das obras de arte selecionadas para a prática pedagógica como conscientes para a educação. Tal preocupação está diretamente ligada aos currículos e aos objetivos pedagógicos do ensino da arte e no enfoque didático dado à formação dos professores.

Voltando às pesquisas que fazem parte da Rede Observatório de formação de professores em artes visuais, as questões aqui pinceladas, como arte, educação, obra de arte, currículo e formação docente não são exclusivas das pesquisas da Rede, o diferencial do grupo está no seu enfoque investigativo a partir do materialismo histórico dialético e deve procurar se firmar nesse campo de estudo, pois nasce da necessidade de conhecer para transformar. O conceito de rede é bastante significativo, pois sugere um tramado que não nasceu pronto, mas foi tecido pelo trabalho, categoria central para compreender o homem e a sua arte a partir do seu território material e social.

\section{REFERÊNCIAS}

FISCHER, Ernst. A necessidade da arte. 9. ed. Rio de Janeiro: Guanabara, 2002.

GAMBOA, Silvio Ancízar Sanchez. Pesquisa em Educação: métodos e epistemologias. Chapecó, SC: Argos, 2007.

FISCHER, Ernst. Pesquisa qualitativa: superando tecnicismos e falsos dualismos. Contrapontos - volume 3 n. 3 - p. 393-405 - Itajaí, set./dez. 2003

GOLDMANN, Lucien. Ciências humanas e filosofia: que é a sociologia? 12. ed. Rio de Janeiro: Bertrand Brasil, 1993.

KONDER, Leandro. Os marxistas e a arte: breve estudo histórico-crítico de algumas tendências da estética marxista. Rio de Janeiro: Civilização Brasileira, 1967. 243p.

LUKÁCS, Gÿorgy. Marxismo e teoria da literatura. Seleção, apresentação e tradução de Nelson Coutinho. 2.ed. São Paulo: Expressão Popular, 2010.

LUKÁCS, Gÿorgy. Introdução a uma Estética Marxista. Sobre a categoria da particularidade. Tradução de Carlos Nelson Coutinho e Leandro Konder. Rio de Janeiro: civilização Brasileira, 1968.

MARX, Karl. Produção, Consumo, Distribuição, Troca (Circulação) in: Introdução à Contribuição para a Crítica da Economia Política. 1859.

MARX, Karl; ENGELS, Friedrich. Cultura, arte e literatura: textos escolhidos. Tradução de José Paulo e Miguel Makoto Cavalcanti Yoshida. 1.ed. São Paulo: Expressão Popular, 2010.

MÉSZÁROS, István. O desafio e o fardo do tempo histórico: o socialismo no século XXI. São: Boitempo, 2007. 396 p.

NETTO, JOSÉ Paulo. Introdução ao estudo do método de Marx. São Paulo: Expressão Popular,2011.

SÁNCHEZ VÁZQUEZ, Adolfo. Convite à Estética. Rio de Janeiro: Civilização Brasileira, 1999. 
SAVIANI, Dermeval. Pedagogia Histórico-Crítica: primeiras aproximações. 4. ed. Campinas: Autores Associados, 1994.139p

SAVIANI, Dermeval. História das ideias pedagógicas no Brasil. Campinas, SP: Autores Associados, 2007. $472 \mathrm{p}$.

SOARES, Rosana. Concepções Pedagógicas nos Currículos de Artes Visuais em Santa Catarina, 2009. Disponível em: http://tede.udesc.br/tede/tede/837

SOARES, Rosana. A Educação Estética como Possibilidade de Emancipação dos Sujeitos no Ensino da Arte: Desdobramentos e Implicações. 355 f. il. 2015. Tese (Doutorado) - Programa de Pós-Graduação em Educação, Universidade Federal da Bahia, Salvador, 2015. 